\title{
AVALIAÇÃO MULTICRITERIAL NO MAPEAMENTO DE RISCO DE INCÊNDIOS FLORESTAIS, EM AMBIENTE SIG, NA BACIA DO RIO CORUMBATAÍ, SP ${ }^{1}$
}

\author{
Hilton Luis Ferraz da Silveira ${ }^{2}$, Carlos Alberto Vettorazzi $^{3}$ e Roberta de Oliveira Averna Valente ${ }^{4}$
}

\begin{abstract}
RESUMO - Um dos agentes mais empregados na supressão de áreas florestais no Estado de São Paulo é o fogo, por meio de queimadas que, quando fora de controle, podem converter-se em incêndios responsáveis pela destruição de extensos ecossistemas. Na Bacia do Rio Corumbataí, SP, os incêndios são um dos causadores de fragmentação e degradação da cobertura florestal. Nesse contexto, este trabalho objetivou a realização do mapeamento de risco de incêndios florestais na Bacia do Rio Corumbataí, utilizando-se a avaliação multicriterial (Método da Média Ponderada Ordenada) em um Sistema de Informações Geográficas. Os fatores importantes do estudo foram: declividade do terreno, face de exposição ao sol, pluviosidade, proximidade da malha viária, proximidade dos centros urbanos, proximidade da rede hidrográfica, vizinhança dos fragmentos e face de exposição aos ventos. A combinação dos mapas de fatores resultou no mapa de risco regional da bacia. Para a confecção do mapa de risco em nível de fragmento, determinou-se o risco associado a cada fragmento, a partir da análise de uma faixa de $30 \mathrm{~m}$ em seu entorno. O risco foi reclassificado em três classes: baixo, médio e alto. Com base no mapa final, verificou-se que: aproximadamente $20 \%$ dos fragmentos de mata nativa pertencem à classe de risco alto, $55 \%$ à classe de risco médio e $25 \%$ à classe de risco baixo. Nas condições atuais de uso e cobertura do solo, bem como de manejo das áreas agrícolas e pastagens, os remanescentes florestais da Bacia do Rio Corumbataí estão sob séria ameaça de degradação por incêndios florestais.
\end{abstract}

Palavras-chave: Suporte à decisão, média ponderada ordenada e conservação florestal.

\section{MULTI-CRITERIA EVALUATION OF A GIS ENVIRONMENT IN A FOREST FIRE HAZARD MAPPING FOR THE CORUMBATAÍ RIVER BASIN, SP, BRAZIL}

\begin{abstract}
Fire is one of the agents most used in the suppression of forest areas in the State of São Paulo, Brazil, and, when out of control, it can be responsible for the destruction of extensive ecosystems. In the case of the Corumbatai river basin, SP, fire is one of the main causes of forest fragmentation and degradation. The purpose of this study was to map forest fire hazard for the Corumbatai river basin, using multi-criteria evaluation (Ordered Weighted Average method) using a Geographic Information System. Factors considered important to the study were: slope; aspect; rainfall; proximity to roads; proximity to urban areas; proximity to water; forest fragment neighborhood; and wind exposure. The combination of these factors resulted in a regional fire hazard map for the river basin. The analysis of the area just surrounding the forest remnants $(30 \mathrm{~m})$ made it possible to determine the fire hazard in each individual fragment. Such map was reclassified into three hazard levels: low, medium, and high. According to this map, approximately $20 \%$ of the native forest fragments are classified as high-hazard class; $55 \%$ as medium-hazard class; and 25\% as low-hazard class. In the current situation of land use/land cover and management, the forest remnants of the Corumbatai River basin are seriously threatened by fire.
\end{abstract}

Keywords: Decision Support, ordered weighted average and forest conservation.

\footnotetext{
${ }^{1}$ Recebido em 08.11.2006 e aceito para publicação em 20.02.2008.

${ }^{2}$ Empresa Brasileira de Pesquisa Agropecuária (EMBRAPA), CNPS, UEP Nordeste. E-mail : <ferraz@ uep.cnps.embrapa.br $>$.

${ }^{3}$ Departamento de Engenharia Rural da Escola Superior de Agricultura Luiz de Queiroz (ESALQ). E-mail: <cavettor@esalq.usp.br>.

${ }^{4}$ Pós-doutoranda do Departamento de Engenharia Rural da ESALQ/USP. E-mail : <roavalen@ esalq.usp.br>.
} 


\section{INTRODUÇÃO}

Um dos agentes mais usados na supressão de áreas florestais no Estado de São Paulo é o fogo, por meio de queimadas que, quando fora de controle, podem-se converter em incêndios responsáveis pela destruição de extensos ecossistemas. Como conseqüências negativas desses incêndios, podemse citar a perda de biodiversidade; a erosão dos solos; a intensificação do efeito-estufa, pela emissão de gases para a atmosfera; e a própria diminuição da qualidade atmosférica local (SILVA et al., 2003).

Rouw (1994) afirmou que os incêndios causam, ainda, o empobrecimento dos solos e são responsáveis pelo avanço das savanas sobre as florestas tropicais, por contribuírem para o aumento da acidez do solo. Para Guarnieri e Wybo (1995), os incêndios representam um dos maiores problemas para a manutenção e desenvolvimento dos ecossistemas em todo o mundo. A ocorrência de incêndios florestais é motivo de constante preocupação para administradores florestais e tomadores de decisão (NOGUEIRA et al., 2002).

Na Bacia do Rio Corumbataí, SP, os incêndios florestais são um dos responsáveis pela fragmentação e degradação da cobertura florestal remanescente. $\mathrm{O}$ manejo da cultura canavieira, com a utilização de queimadas, representa para os fragmentos florestais uma constante ameaça de início de incêndio. Nesse caso, um facilitador da ação do fogo é o chamado "efeito de borda", por oferecer uma faixa de vegetação mais seca, com presença de gramíneas e, portanto, mais combustível (YAHNER, 1998).

Chen et al. (2001) citaram que o início e a propagação do fogo em áreas florestais podem ser previstos conhecendo-se os fatores humanos, ecológicos e climáticos que participam do processo, como a hidrografia, o uso e cobertura do solo, a geomorfologia e as distâncias às habitações humanas. Segundo Mistry (2005), isso é possível com a aplicação sobre esses dados, de modelos computacionais que avaliam o comportamento potencial do fogo. Esses fatores, por si sós, não constituem informações suficientes para que as entidades responsáveis pelo combate aos incêndios possam agir de maneira eficaz. A integração entre essas informações e, sobretudo, o seu georreferenciamento fornecem aos tomadores de decisão a situação em que se encontram os fragmentos florestais, no que diz respeito ao risco de incêndios e permitem fazer simulações sobre seu estado futuro.

R. Árvore, Viçosa-MG, v.32, n.2, p.259-268, 2008
Desse modo, se o início e a propagação dos incêndios florestais podem ser previstos, é possível um planejamento envolvendo não somente prevenção, mas também combate, em caso de ocorrência do evento. Vettorazzi et al. (1999) mencionaram que os Sistemas de Informações Geográficas (SIGs), por possibilitarem a análise e modelagem de dados espacialmente referenciados, são um instrumento adequado para o mapeamento e monitoramento de risco de incêndios florestais.

Mistry (2005) citou que a avaliação do risco de incêndios envolve a predição da probabilidade de ignição dentro de uma área, as taxas de propagação e as intensidades prováveis do fogo. Conhecidos os inúmeros aspectos ambientais, físicos e sociais relacionados aos incêndios florestais, faz-se necessário um processo de avaliação interdisciplinar, sistemático, reproduzível, organizado e uniforme, com uma estreita interação entre as suas diversas partes constituintes. Lucena (1999) mencionou que os métodos de avaliação multicriterial podem auxiliar nesse processo de tomada de decisão.

A avaliação multicriterial é uma das técnicas empregadas para a tomada de decisão que foram incorporadas aos SIGs. Essa integração foi considerada um avanço em relação ao procedimento convencional de cruzamento de planos de informação para a determinação de áreas de risco e prioritárias (EASTMAN, 2001; MALCZEWSKI, 1999). Nesse contexto, a avaliação multicriterial é considerada um processo que combina e transforma dados espaciais (planos de informação de entrada) em mapas finais para a tomada de decisão, ressaltando-se que as regras de decisão definem as relações entre os dados de entrada e os mapas finais (MALCZEWSKI, 1999).

Segundo Malczewski (2004), essa avaliação envolve a utilização de dados georreferenciados, os conceitos dos tomadores de decisão e a manipulação desses dados e conceitos com base em regras de decisão específicas. Para esse autor, duas considerações são, dessa forma, de extrema importância para a utilização da avaliação multicriterial: (i) a capacidade do SIG de adquirir, armazenar, recuperar, manipular e analisar os dados georreferenciados e (ii) a capacidade de combinar esses dados e os conceitos dos tomadores de decisão em alternativas de decisão.

Os conceitos dos tomadores de decisão são expressos pelos critérios que, de acordo com Eastman 
(2001), são a base do processo e podem ser medidos e avaliados. Para esse autor, o critério é a evidência sobre a qual um indivíduo pode ser designado a um conjunto de decisão. Os critérios podem ser de dois tipos: fatores e restrições e podem referir-se tanto a atributos do indivíduo quanto ao conjunto todo de decisão (EASTMAN, 2001).

Os fatores irão realçar ou diminuir a suscetibilidade de uma alternativa específica para uma atividade ou objetivo (EASTMAN, 2001). Para Randhir et al. (2001), os fatores utilizados no processo de tomada de decisão são aqueles que representam as características críticas de um habitat.

As restrições podem ser entendidas como categorias restritivas das alternativas (fatores), excluindo áreas e limitando espacialmente a distribuição das possibilidades de escolha (EASTMAN, 2001).

Como métodos da avaliação multicriterial que vêm sendo utilizados na integração dos diferentes critérios, podem-se citar o Booleano; o do Ponto Ideal; o da Combinação Linear Ponderada; o da Análise de Concordância; e, mais recentemente, o da Média Ponderada Ordenada (MALCZEWSKI, 2000). Entre esses métodos, a Combinação Linear Ponderada e a Média Ponderada Ordenada têm sido empregadas em substituição à lógica boolena na determinação de áreas suscetíveis, de risco e prioritárias (MALCZEWSKI, 1999; EASTMAN, 2001; MALCZEWSKI, 2004).

Nesse contexto, este trabalho objetivou o mapeamento de risco de incêndios florestais na Bacia do Rio Corumbataí, utilizando-se a avaliação multicriterial (Método da Média Ponderada Ordenada) em um Sistema de Informações Geográficas.

\section{MATERIAL E MÉTODOS}

\section{1. Área de Estudo}

A Bacia do Rio Corumbataí localiza-se na porção centro-leste do Estado de São Paulo, entre as latitudes $22^{\circ} 04^{\prime} 46^{\prime \prime} \mathrm{S}$ e $22^{\circ} 41^{\prime} 28^{\prime \prime} \mathrm{S}$ e longitudes 47²6'23'W e $47^{\circ} 56^{\prime} 15^{\prime \prime} \mathrm{W}$, abrangendo uma área de aproximadamente 170.000 ha. Seu relevo é composto por morrotes alongados e espigões e por colinas médias e amplas (KOFFLER, 1993).

O clima da região, na classificação de Köppen, é do tipo Cwa, caracterizado como subtropical, seco no inverno e chuvoso no verão, com temperatura média do mês mais quente superior a $22{ }^{\circ} \mathrm{C}$ (SALATI, 1996). As precipitações caracterizam-se por valores acima de $1.000 \mathrm{~mm}$ na estação chuvosa, associadas a altitudes entre $800 \mathrm{~m}$ e $1.000 \mathrm{~m}$ (porção norte da bacia) (ZAVATINI e CANO, 1993). Os ventos predominam no sentido SENW (SETZER, 1966; MONTEIRO, 1973).

A implantação da cana-de-açúcar, no início do século XIX, marcou o processo de ocupação antrópica da região. Com o avanço da cultura do café, a partir de 1850 as áreas de floresta nativa foram substituídas rapidamente pelas culturas agrícolas, sobretudo com o advento da ferrovia (ramal rio-clarense), ocorrido no ano de 1876 (HÖFLING, 2003).

$\mathrm{Na}$ atualidade, a bacia apresenta intenso desenvolvimento agrícola, sendo ocupada principalmente por cana-de-açúcar e por pastagens que, segundo Valente (2005), representam $44 \%$ e $26 \%$ do uso e cobertura do solo, respectivamente. Esse autora ressaltou que essa matriz agrícola levou à diminuição da área ocupada por florestas e ao processo de fragmentação florestal, restringindo-se as áreas de floresta nativa (Floresta Estacional Semidecidual) e Savana Florestada (Cerrado lato sensu) a apenas $11 \%$ e $0,7 \%$, respectivamente, do total da bacia. Neste trabalho, essas duas formações foram consideradas como floresta.

\subsection{Avaliação Multicriterial}

Para o mapeamento de risco de incêndios com a avaliação multicriterial, empregou-se o método da Média Ponderada Ordenada (MPO) no ambiente de um SIG (IDRISI Kilimanjaro), que também foi utilizado na geração dos planos de informação e mapas de critérios. Esse método teve sua conceituação matemática estabelecida por Yager (1988) e envolve a aplicação de dois grupos de pesos: os de fatores e os de ordenação, além da definição do próprio conjunto de fatores. O primeiro grupo de pesos relaciona-se à importância do fator no processo de tomada de decisão, e o segundo controla a maneira pela qual os pesos de fatores serão agregados, além de permitir a determinação do nível de compensação entre os fatores e o risco assumido no processo de tomada de decisão.

\section{Critérios}

Na definição dos critérios e, posteriormente, dos pesos de fatores, empregou-se a Técnica Participatória

R. Árvore, Viçosa-MG, v.32, n.2, p.259-268, 2008 
proposta por Eastman (2001), Malczewski (1999) e Chen et al. (2000), que se constitui na reunião e consulta a especialistas das diferentes áreas de interesse do trabalho, além de uma revisão bibliográfica. Os fatores considerados importantes aos objetivos do trabalho foram:

(1) Face de exposição ao sol: a importância desse fator, de acordo com Pezzopane et al. (2001), é função da disponibilidade energética para a redução da umidade do material combustível. As faces de maior risco de incêndios são aquelas de maior exposição ao sol. No caso da bacia são, em ordem decrescente, as faces Norte, Oeste, Sul e Leste. Dessa forma, produziuse esse plano de informação a partir do Modelo Numérico do Terreno da bacia. Ressalta-se que esse mapa de fator, assim como os demais, foi normalizado para uma escala comum, com variação de 0 a 255 bytes, de maneira a preservar as relações de risco previamente estabelecidas e permitir a posterior combinação dos diferentes mapas de fatores. No caso desse fator, empregou-se, nessa normalização, uma função linear crescente.

(2) Declividade do terreno: sua relevância é em razão de o maior risco de incêndios florestais estar associado aos maiores valores de declividade (PEZZOPANE et al., 2001). Foi produzido a partir do Modelo Numérico do Terreno da bacia e adotandose os intervalos de classe (Quadro 1) propostos por Jaiswal et al. (2002), para trabalhos de risco de incêndios florestais. Para sua normalização (Quadro 1), também se empregou uma função linear crescente.

(3) Pluviosidade: a relação entre o maior estresse hídrico, causado principalmente pela seca e por diferenças na distribuição das chuvas, e a maior incidência e extensão dos incêndios florestais é ressaltada por Nelson (2001). Neste estudo, consideraram-se, dessa forma, as médias mensais de chuva para os cinco meses mais secos do ano, nos quais o maior risco de incêndios é função do estresse hídrico da vegetação. Com a interpolação (método da triangulação irregular) dos dados referentes às estações meteorológicas da região, obteve-se a distribuição pluviométrica na bacia. Essa distribuição foi normalizada para a escala de 0 a 255 bytes, por meio de uma função linear decrescente, 0 que possibilitou associar os maiores valores de precipitação aos menores valores de risco de incêndios florestais.

R. Árvore, Viçosa-MG, v.32, n.2, p.259-268, 2008
Quadro 1 - Classes de declividade, normalizadas para a escala de 0-255 bytes, da Bacia do Rio Corumbataí, SP Table1 - Slope classes, standardized to a scale of 0-255bytes, for the Corumbatai River Basin, SP

\begin{tabular}{cc}
\hline Classes de & Escala de \\
Declividade $(\%)$ & $0-255$ bytes \\
\hline $0-3$ & $1-8$ \\
$3-5$ & $8-13$ \\
$5-10$ & $13-25$ \\
$10-15$ & $25-38$ \\
$15-35$ & $38-89$ \\
$>35$ & $89-255$ \\
\hline
\end{tabular}

(4) Proximidade à malha viária: as áreas marginais às rodovias estão relacionadas ao alto risco de incêndios florestais porque, segundo Ferraz e Vettorazzi (1998) e Silva et al. (2004), são áreas sujeitas a incêndios de veículos, cargas e fogueiras produzidas por transeuntes. Para a geração desse mapa de fator, produziuse o mapa de distância à malha viária. $\mathrm{O}$ mapa final foi normalizado para a escala $0-255$ bytes, por meio de uma função linear decrescente. Dessa forma, as áreas mais próximas à malha viária (maior risco) assumiram valores mais próximos a 255 bytes.

(5) Proximidade aos centros urbanos: os fragmentos próximos aos centros urbanos sofrem com a constante ameaça de redução de sua área ou, mesmo, de sua extinção total, em função do uso inadequado dessas áreas (GUTZWILLER e BARROW, 2003), além das ameaças similares àquelas sofridas por fragmentos próximos à malha viária (CHEN et al., 2001). Para esse mapa de fator, produziu-se o mapa de distância aos centros urbanos e, de maneira similar ao anterior, o mapa final foi normalizado para a escala $0-255$ bytes, por meio de uma função linear decrescente. Dessa forma, as áreas mais próximas aos centros urbanos (maior risco) também assumiram valores mais próximos a 255 bytes.

(6) Proximidade à rede hidrográfica: Forman e Collinge (1997) ressaltaram que os corpos d'água podem ser considerados uma barreira à propagação do fogo. Dessa maneira, o mapa de distâncias aos corpos d'água foi normalizado (escala $0-255$ bytes) por meio de uma função linear crescente, e, conseqüentemente, as áreas mais próximas a eles assumiram os menores valores nessa escala comum. 
(7) Vizinhança aos fragmentos de floresta: na bacia, os fragmentos de floresta estão inseridos em uma matriz predominantemente agrícola, em que os usos e coberturas do solo influenciam, de diferentes maneiras, o risco de incêndios. A consulta a especialistas e à literatura (FERRAZ e VETTORAZZI, 1998; PEZZOPANE etal., 2001; MISTRY, 2005) possibilitou avaliar a influência, do ponto de vista do risco de incêndios, dos diferentes usos e coberturas do solo sobre os fragmentos de floresta da bacia (Quadro 2). Essa avaliação considerou, também, a área ocupada e a distribuição espacial das culturas na bacia, ou seja, sua estrutura. Os pesos associados aos usos e coberturas do solo, padronizados para a escala comum, são apresentados no Quadro 2. Assim, quanto menor o risco de incêndios relacionado a um fragmento de floresta, menor o peso associado ao uso e cobertura do solo. Considerou-se, ainda, a variável distância, visto que o uso e cobertura do solo terão maior influência quanto mais próximo estiver de um fragmento de floresta. Para a produção desse mapa de fator houve, portanto, a combinação de dois fatores: a vizinhança e a distância aos fragmentos de floresta. Para a obtenção do mapa de distâncias na escala comum, utilizou-se uma função linear decrescente porque, como mencionado, quanto mais próximo um vizinho estiver de um fragmento, maior a sua influência. Com a combinação desses dois fatores (vizinhança e distância aos fragmentos) houve, assim, a necessidade de utilizar um novo contraste linear para produzir o mapa final do fator com variação entre 0 e 255 bytes.

(8) Face de exposição aos ventos: fator importante quando se trata da propagação dos incêndios porque o vento, além de atuar como agente que retira a umidade da matéria orgânica, oferece, de forma contínua, o comburente oxigênio (PEZZOPANE etal., 2001; FERRAZ e VETTORAZZI, 2003). Segundo Setzer(1966) e Monteiro (1973), as faces voltadas para sudeste são as que recebem diretamente os ventos predominantes na região, que ocorrem no sentido SE-NW. Para associar os maiores valores, na escala comum, às vertentes de maior exposição aos ventos predominantes, houve a necessidade de normalização desse fator por meio de uma função linear crescente.

Os mapas de fatores proximidade aos centros urbanos, vizinhança aos fragmentos de floresta e pluviosidade foram gerados, respectivamente, a partir do plano de informação, uso e cobertura do solo produzido por Valente (2005) e dos dados de precipitação diária obtidos no Banco de Dados Hidrometeorológicos do Departamento de Águas e Energia Elétrica do Estado de São Paulo. Os demais mapas de fatores tiveram por base os planos de informação do banco de dados cartográficos do Laboratório de Geoprocessamento do Departamento de Engenharia Rural da ESALQ/USP.

No que diz respeito às restrições, considerouse o limite da bacia, ou seja, o risco de incêndios foi gerado apenas na área de estudo. Também, foram eliminadas as áreas em que não faz sentido a determinação de risco de incêndios florestais, como áreas urbanas, estradas etc.

\section{Pesos dos mapas de fatores}

Para definir o primeiro grupo de pesos, os chamados pesos de fatores, por meio da Técnica Participatória (EASTMAN, 2001), utilizou-se o método da Comparação Pareada, proposto por Saaty (1977) no contexto do Processo Hierárquico Analítico. Elaborou-se uma matriz de comparação pareada entre os fatores (Quadro 3), de acordo com a importância relativa entre pares de fatores, utilizando como referência uma escala contínua de nove pontos (Figura 1).

A escolha da matriz considerou a Taxa de Consistência (TC) e a ordem de importância dos fatores previamente estabelecida (Técnica Participatória e revisão de literatura). Segundo Saaty (1980), a TC indica a probabilidade de que os valores de comparação entre os fatores tenham sido gerados aleatoriamente. $\mathrm{O}$ referido autor citou que os valores de TC devem sempre estar abaixo de 0,10 e, no caso de estarem acima desse valor, há a necessidade de reorganização da matriz, alterandose os valores de comparação entre os fatores.

Quadro 2 - Pesos associados aos usos e coberturas do solo na Bacia do Rio Corumbataí e padronizados para uma escala comum

Table 2 - Weights associated with land use/land cover for the Corumbatai River basin and standardized to a common scale

\begin{tabular}{lcc}
\hline $\begin{array}{l}\text { Uso e Cobertura } \\
\text { do Solo }\end{array}$ & Peso & $\begin{array}{c}\text { Escala de } \\
0-255 \text { bytes }\end{array}$ \\
\hline Floresta plantada & 1 & 1 \\
Cultura anual & 2 & 63 \\
Fruticultura & 3 & 127 \\
Pastagem & 4 & 190 \\
Cana-de-açúcar & 5 & 255 \\
\hline
\end{tabular}

R. Árvore, Viçosa-MG, v.32, n.2, p.259-268, 2008 
Quadro 3 - Matriz de comparação pareada entre os mapas de fatores de risco de incêndios florestais na Bacia do Rio Corumbataí Table 3 - Pairwise comparison matrix for forest fire hazard mapping for the Corumbatai River basin

\begin{tabular}{|c|c|c|c|c|c|c|c|c|c|c|}
\hline Fatores & $\begin{array}{c}\text { Face } \\
\text { sol }\end{array}$ & Decl. & $\begin{array}{l}\text { Prox. } \\
\text { Rede }\end{array}$ & $\begin{array}{c}\text { Prox. } \\
\text { Urb. }\end{array}$ & $\begin{array}{l}\text { Prox. } \\
\text { Malha }\end{array}$ & Pluvios. & $\begin{array}{c}\text { Face } \\
\text { Vento } \\
\end{array}$ & Vizinh. & $\begin{array}{c}\text { Pesos de } \\
\text { Fatores } \\
\end{array}$ & $\begin{array}{c}\text { Pesos de } \\
\text { Ordenação }\end{array}$ \\
\hline Face sol & 1 & & & & & & & & 0,1386 & 0,06 \\
\hline Decl.1,5 & 1 & & & & & & & & 0,2181 & 0,08 \\
\hline Prox. rede & 0,5 & 0,3 & 1 & & & & & & 0,0586 & 0,15 \\
\hline Prox. urb. & 0,5 & 0,4 & 1,5 & 1 & & & & & 0,0275 & 0,05 \\
\hline Prox. malha & 0,8 & 0,5 & 2,0 & 1,3 & 1 & & & & 0,1237 & 0,06 \\
\hline Pluvios. & 0,2 & 0,1 & 0,5 & 0,3 & 0,3 & 1 & & & 0,0275 & 0,10 \\
\hline Face vento & 1,2 & 0,8 & 3,0 & 2,0 & 1,5 & 6,0 & 1 & & 0,1673 & 0,23 \\
\hline Vizinh. & 1,5 & 0,9 & 3,5 & 2,3 & 1,8 & 7,0 & 1,1 & 1 & 0,1825 & 0,27 \\
\hline
\end{tabular}

Face sol: face de exposição ao sol; decl.: declividade do terreno; Prox. rede: proximidade à rede hidrográfica; Prox. urb: proximidades aos centros urbanos; Prox. malha: proximidade à malha viária; pluvios.: Pluviosidade; face vento: face de exposição aos ventos; e Vizinh.: vizinhança aos fragmentos de floresta.

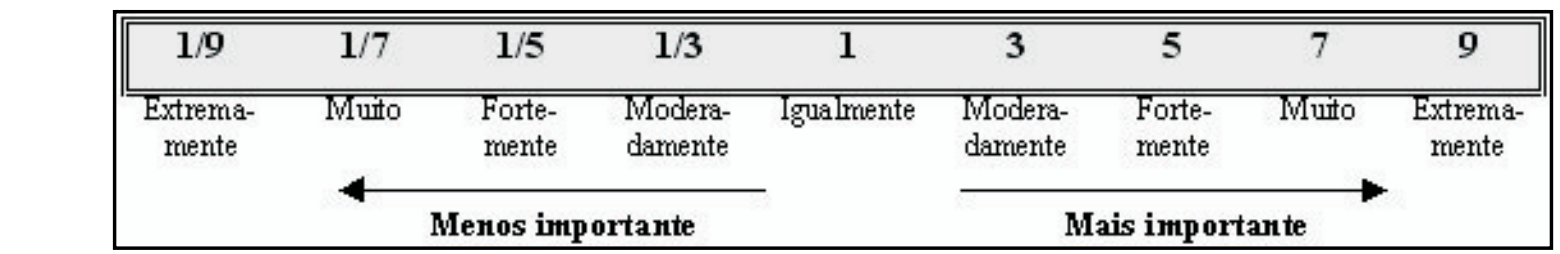

Fonte: Eastman, 2001.

Figura 1 - Escala contínua para elaboração da matriz de comparação pareada.

Figure 1 - The continuous rating scale used for preparing the pair-wise comparison matrix.

O segundo grupo de pesos, os chamados pesos de ordenação, foi determinado dentro do espaço de estratégia de decisão (Figura 2) e pode ser observado no Quadro 3. A maneira como os fatores serão compensados é que controla o modo como o operador (Média Ponderada Ordenada) agrega os fatores, no continuum entre os extremos (AND e OR) (EASTMAN, 2001). Se a maior parte dos pesos de ordenação for assinalada à esquerda, à direita ou ao centro (Figura 2), isso irá determinar a posição na dimensão de risco assumido no processo de tomada de decisão (MALCZEWSKI, 1999).

O valor da compensação entre os fatores e o risco assumido no processo de tomada de decisão foram definidos da seguinte maneira:

Risco $=\frac{1}{\mathrm{n}-1} \sum[(\mathrm{n}-1) \mathrm{Oi}] ; \mathrm{e}$

Compensação $=1-\sqrt{\frac{\sum(\mathrm{Wi}-1 / \mathrm{n})^{2}}{\mathrm{n}-1}}$

sendo $\mathrm{n}=$ número total de fatores; $\mathrm{i}=$ ordem do fator; $\mathrm{Oi}=$ peso do fator para o fator de ordem $\mathrm{i}$; e Wi = peso para o fator da i-ésima ordem.

R. Árvore, Viçosa-MG, v.32, n.2, p.259-268, 2008
A caracterização do risco assumido no processo de tomada de decisão, como alto, médio-alto, médiobaixo e baixo, seguiu os intervalos de risco propostos por Valente e Vettorazzi (2005), respectivamente: 0,00 a 0,$40 ; 0,40$ a 0,$50 ; 0,50$ a 0,$60 ;$ e 0,60 a 1,00 .

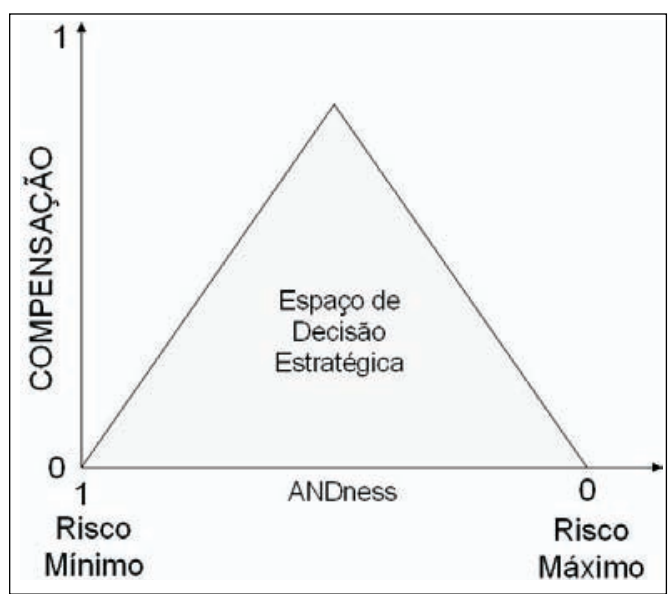

Adaptada de Eastman, 2001.

Figura 2 - Espaço de estratégia para a tomada de decisão. Figure 2-Strategy space for decision-making. 
Ressalta-se que para definir os pesos de ordenação houve, conforme proposto por Valente e Vettorazzi (2005), a análise prévia do comportamento (ordem de ranqueamento) de cada fator. Associando todo o peso de ordenação (totalizando 1) a cada um dos mapas de fatores, foi obtido, sucessivamente, o seguinte ranqueamento dos fatores: declividade; vizinhança; face de exposição ao sol; face de exposição ao vento; proximidade à malha viária; proximidade aos centros urbanos; proximidade à rede hidrográfica; e precipitação.

\section{Mapas de risco de incêndios}

Com os pesos de fator e de ordenação, foi possível combinar os mapas de critérios (pelo método da Média Ponderada Ordenada) e gerar o mapa regional de risco de incêndios florestais para a bacia. Para o entendimento da distribuição espacial do risco de incêndios na paisagem, esse mapa foi reclassificado em cinco classes de risco: muito baixo, baixo, médio, alto e muito alto.

Para produzir o mapa de risco de incêndios em nível de fragmento, determinou-se o risco médio de uma faixa de $30 \mathrm{~m}$ ao redor de cada fragmento. Os fragmentos foram classificados de maneira a apresentar três classes de risco: baixo, médio e alto. Agruparamse, para isso, os fragmentos que estavam em regiões de riscos muito baixo e baixo de incêndio, assim como aqueles que estavam em regiões de riscos alto e muito alto.

\section{RESULTADOS E DISCUSSÃO}

A combinação dos mapas de fatores gerou um mapa regional de risco de incêndios para a Bacia do Rio Corumbataí (Figura 3a), que apresentou risco alto $(\mathrm{R}=0,35)$ para o processo de tomada de decisão e $84 \%$ de compensação entre seus fatores. Nem sempre a melhor solução é aquela associada ao menor risco (MALCZEWSKI, 1999). As características da paisagem devem ser consideradas, mesmo se isso implicar soluções arriscadas (VALENTE e VETTORAZZI, 2005). A bacia, de acordo com esse mapa, possui aproximadamente $21 \%$ de sua área com risco muito alto de incêndios florestais, $20 \%$ com risco médio, $20 \%$ com risco baixo, $20 \%$ com risco alto e $19 \%$ com risco muito baixo.

A distribuição das classes de risco de incêndios, associada às próprias características dos fragmentos de floresta, principalmente sua área e forma (na maioria irregular), resulta no mapa de risco de incêndios por fragmento (Figura 3b), com 55\% dos remanescentes de floresta apresentando risco médio, $25 \%$ risco baixo e $20 \%$ risco alto.
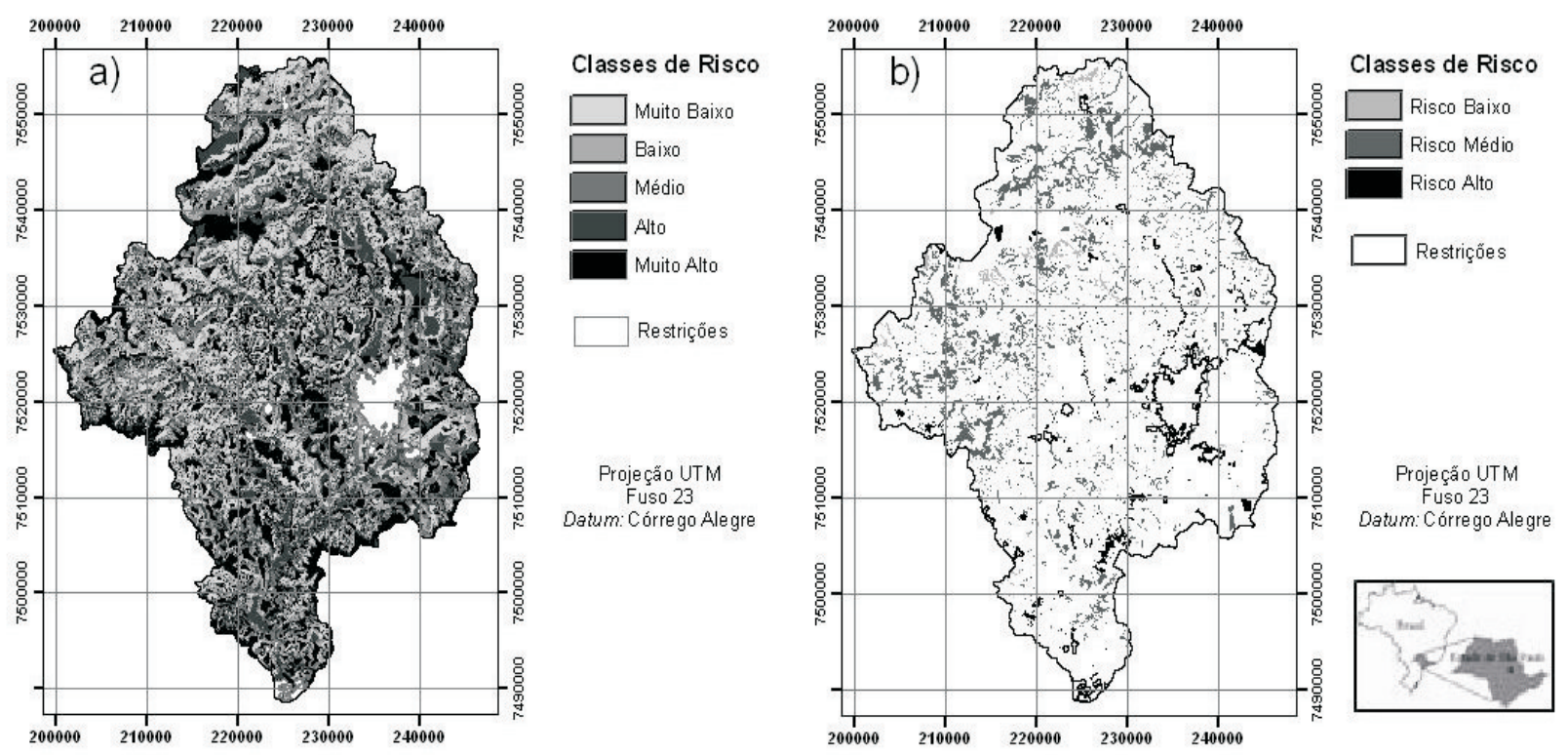

Figura 3 - Risco de incêndios florestais na Bacia do Rio Corumbataí: (a) regional e (b) por fragmento. Figure 3 - Forest fire hazard maps for the Corumbatai River basin: (a) regional and (b) by fragment. 
A espacialização do risco de incêndios florestais na bacia está intrinsecamente relacionada à importância e influência dos mapas de fatores. Os fatores relacionados ao relevo, como a declividade, a face de exposição ao vento e a face de exposição ao sol, somam, aproximadamente, $43 \%$ dos pesos de fatores e assumem, na ordem de ranqueamento, as primeiras posições. A declividade assumiu o primeiro lugar nessa ordenação; a face de exposição ao sol o terceiro, seguida pela face de exposição ao vento. Mesmo com a alta compensação (alto peso de fator e baixo peso de ordenação) de dois desses fatores (declividade e face de exposição ao sol) houve forte influência deles na distribuição do risco de incêndios. Pode-se dizer que foram os critérios que mais influenciaram a agregação dos fatores, ressaltando, principalmente, a influência da declividade (primeiro no ranqueamento dos fatores).

Outro fator que exerceu forte influência no risco de incêndios para a bacia foi a vizinhança, em função dos pesos associados a esse fator, ou seja, a importância e a influência que ele possui para o risco de incêndios, associadas ao fato de ele ser o segundo fator na ordem de ranqueamento. Por consequiência, no mapa regional a ocupação da classe de risco muito alto coincidiu aproximadamente com a distribuição da cana-de-açúcar na bacia (cultura de maior influência negativa sobre os fragmentos - Quadro 2), ou seja, predominantemente em suas porções leste e sul. Nogueira et al. (2002) já haviam constatado essa relação entre o manejo da canade-açúcar e o alto risco de incêndios florestais.

As regiões da bacia, por sua vez, com culturas que receberam menor peso de influência (Quadro 2), foram associadas a menores riscos de incêndio. A distribuição dos fragmentos de baixo risco de incêndios (Figura 3b), por exemplo, coincide com aquela das pastagens (principalmente região noroeste da bacia), entre outras características dessa paisagem. Os fragmentos dessa região foram considerados por Valente (2005) como prioritários à conservação florestal. Podese dizer, portanto, que os pesos associados ao fator vizinhança possibilitam incluir o mapeamento de risco no contexto dos trabalhos de conservação da cobertura florestal e, sobretudo, de estruturação da Bacia do Rio Corumbataí.

Como resultado da associação dos fatores de maior ranqueamento (relacionados ao relevo e à vizinhança), notou-se, principalmente no mapa regional (Figura 3a), que não existe a "continuidade" entre as classes de risco, ou seja, áreas de mesmo risco de incêndios não estão necessariamente interligadas. Essa característica também foi observada por Ferraz e Vettorazzi (2003), quando utilizaram fatores relacionados ao relevo e ao uso e cobertura do solo em mapeamento de risco.

Outra característica a ser ressaltada no mapeamento de risco é a proximidade às estradas e aos centros urbanos. Os fragmentos próximos aos centros urbanos sofrem com a constante ameaça de redução de sua área ou, mesmo, de sua extinção total, em função do uso inadequado dessas áreas (GUTZWILLER e BARROW, 2003), além das ameaças similares àquelas sofridas por fragmentos próximos à malha viária (CHEN et al., 2001). Por esses motivos, que foram refletidos nos pesos desses fatores, associados às suas próprias ordens de ranqueamento, é que se observa que as classes de maior risco estão associadas à maior concentração (presença) de estradas e centros urbanos.

A proximidade à rede hidrográfica, por sua vez, foi um dos fatores de menor influência nesse mapeamento. Sua baixa influência é função da importância a que foi relacionada no processo de tomada de decisão e também da sua posição na ordem de ranqueamento dos fatores. Dessa maneira, a rede hidrográfica em geral está associada a todos os níveis de risco de incêndios florestais. Não se pode desconsiderar a própria distribuição dos cursos d'água por toda a área da bacia. No entanto, observando dois locais, um com e outro sem a presença de cursos d’água, notou-se que no primeiro caso foi atribuído menor risco de incêndios. Esse fator apresenta, dessa forma, influência local para o mapeamento.

O fator pluviosidade (última posição no ranqueamento dos fatores) comportou-se de maneira semelhante à proximidade à rede hidrográfica, em função da homogeneidade de sua distribuição na área de estudo, além dos pesos associados a ele.

Pode-se dizer, assim, que os fatores e pesos empregados possibilitaram o mapeamento de risco de incêndios conforme preestabelecido para esse processo de tomada de decisão, ou seja, considerando as características da paisagem e, sobretudo, a sua estrutura.

\section{CONCLUSÕES}

Para as condições em que o trabalho foi realizado, conclui-se que:

§ A avaliação multicriterial, por meio do Método

\section{R. Árvore, Viçosa-MG, v.32, n.2, p.259-268, 2008}


da Média Ponderada Ordenada, permite o mapeamento de risco de incêndios florestais. A utilização do método, contudo, é fortemente influenciada pelo conhecimento do fenômeno a ser mapeado, assim como das características da paisagem. Esse conhecimento determina a robustez da solução para o processo de tomada de decisão.

$\S$ Em termos de área, para as atuais condições da bacia há um equilíbrio na distribuição espacial das classes de risco de incêndios florestais.

$\S$ Em nível de fragmento, a grande maioria dos remanescentes florestais da bacia está sob risco médio ou alto de incêndios.

\section{AGRADECIMENTO}

À Fundação de Amparo à Pesquisa do Estado de São Paulo (FAPESP), pela bolsa de estudos concedida ao primeiro autor.

\section{REFERÊNCIAS}

CHEN, K. P.; BLONG, R.; JACOBSON, C. MCERISK: Integrating multicriteria evaluation and GIS for risk decision-making in natural hazards. Environmental Modelling \& Software, v.16, n.4, p.387-397, 2001.

EASTMAN, J. R. Decision support: strategy analysis. Idrisi 32: Guide to GIS and image processing. Worcester: Clark Labs, Clark University, 2001. v.2.22p.

FERRAZ, S. F. B.; VETTORAZZI, C. A. Mapeamento de risco de incêndios florestais por meio de sistema de informações geográficas.

Scientia Forestalis, n.53, n.1, p.39-48, 1998.

FERRAZ, S. F. B.; VETTORAZZI, C. A. Identificação de áreas para recomposição florestal com base em princípios de Ecologia da Paisagem. Revista Árvore, v.27, n.4, p.575-583, 2003.

FORMAN, R. T. T.; COLLINGE, S. K. Nature conserved in changing landscapes with and without spatial planning. Landscape and Urban Planning, v.37, n.1, p.129-135, 1997.

GUARNIERI, F.; WYBO, J. L. Spatial decision support and information management application to wild land fire prevention: the Wilfried system. Safety Science, v.20, n.1, p.3-12. 1995.
GUTZWILLER, K. J.; BARROW, W. C.

Influences of roads and development on bird communities in protected Chihuahuan Desert landscapes. Biological Conservation, v.113, n.2, p.225-237, 2003.

HÖFLING, M. A. Z. As páginas de história. Caderno Cedes, v.23, n.60, p.179-188, 2003.

JAISWAL, R. K. et al. Forest fire risk zone mapping from satellite imagery and GIS.

International Journal of Applied Earth Observation and

Geoinformation, v.14, n.1, p.1-10, 2002.

JIANG, H.; EASTMAN, J. R. Application of fuzzy measures in multi-criteria evaluation in GIS. International Journal of Geographical Information Science, v.14, n.2, p.173-184, 2000.

KOFFLER, N. F. Uso das terras da bacia do Rio Corumbataí em 1990. Geografia, v.18, n.1, p.135-150, 1993.

LUCENA, L. F. L. A análise multicriterial na avaliação de impactos ambientais. In.: ENCONTRO NACIONAL DA SOCIEDADE BRASILEIRA DE ECONOMIA ECOLÓGICA, 3., 1999, Recife. Anais... Recife: SBEE, 1999. p.1-13.

MALCZEWSKI, J. GIS and multicriteria decision analysis. New York: John Wiley, 1999.362p.

MALCZEWSKI, J. On the use of weighted linear combination method in GIS. Transactions in GIS, v.4, n.1, p.5-22, 2000.

MALCZEWSKI, J. GIS-based land-use suitability analysis: A critical overview. Progress in Planning, v.62, n.1, p.3-65, 2004.

MISTRY, J. Assessing fire potential in a Brazilian Savanna nature reserve. Biotropica, v.37, n.3, p.439-451, 2005.

MONTEIRO, C. A. F. A dinâmica climática e as chuvas no estado de São Paulo. São Paulo: IGEOG/USP, 1973. 130p.

R. Árvore, Viçosa-MG, v.32, n.2, p.259-268, 2008 
NELSON, B. W. Fogo em florestas da Amazônia. In: SIMPÓSIO BRASILEIRODE SENSORIAMENTO REMOTO, 10., 2001, Foz do Iguaçu. Anais... Foz do Iguaçu: INPE 2001. p.1975-1982.

NOGUEIRA, G. S. et al. Escolha de locais para instalação de torres de detecção de incêndio com auxílio do SIG. Revista Árvore, v.26, n.3, p.363-369, 2002.

PEZZOPANE, J. E. M.; OLIVEIRA NETO, S. N.; VILELA, M. F. Risco de incêndios em função da característica do clima, relevo e cobertura do solo. Floresta e Ambiente, v.8, n.1, p.161-165, 2001.

RANDHIR, T. O. et al. A watershed-based land prioritization model for water supply protection. Forest Ecology and Management, v.143, n.1, p.47-56, 2001.

ROUW, A. Effect of fire on soil, rice, weeds and forest regrowth in a rain forest zone (Côte d'Ivoire). Catena, v.22, n.2, p.133-152, 1994.

SAATY, T. A scaling method for priorities in hierarchical structures. Journal

Mathematics Psychology, v.15, NUMERO, p.234-281, 1977.

SAATY, T. The analytic hierarchy process. New York: McGraw-Hill, 1980. 287p.

SALATI, E. Análise ambiental sintético e qualidade da água como subsídio para o planejamento regional integrado da bacia de hidrográfica do rio Corumbataí (SP). 1996. $199 f$. Tese (Doutorado em Cieências da Engenharia Ambiental) - Escola de Engenharia de São Carlos, Universidade de São Paulo, São Carlos, 1996.

SETZER, J. Atlas climático e ecológico do estado de São Paulo. São Paulo: Comissão Interestadual da Bacia Paraná e Uruguai, 1966. 61p.

R. Árvore, Viçosa-MG, v.32, n.2, p.259-268, 2008
SILVA, S. A.; CABRAL, J. B. P.; SCOPEL, I. Incêndios em vegetação entre 2000 e 2002, nas propriedades rurais limítrofes às rodovias pavimentadas do município de Jataí-GO. Jataí. Geoambiente, n.2, p.1-20, 2004. Disponível em: <www.jatai.ufg.br/geo/geoambiente.htm>. Acesso em: 15 de jan. de 2005 .

SILVA, J. C. et al. Avaliação de brigadas de incêndios florestais em unidades de conservação. Revista Árvore, v.27, n.1, p.95-101, 2003.

VALENTE, R. O. A. Definição de áreas prioritárias para conservação e preservação florestal por meio da avaliação multicriterial em ambiente SIG. 2005. 121f. Tese (Doutorado em Recursos Florestais) - Escola Superior de Agricultura "Luiz de Queiroz", Piracicaba, 2005.

VALENTE, R. O. A.; VETTORAZZI, C. A. Comparação entre métodos de avaliação multicriterial, em ambiente SIG, para a conservação e a preservação florestal. Scientia Forestalis, n.69, p.51-61, 2005.

VETTORAZZI, C. A.; FERRAZ, S. F. B.; VALENTE, R. O. A. Monitoramento de risco de incêndios florestais com auxílio de sistemas de informações geográficas. In: SEAB. Sensoriamento remoto e sig aplicados ao planejamento ambiental. Botucatu: FCA/UNESP, 1999. p.45-48.

YAGER, R. R. On ordered weighted averaging aggregation operators in multi-criteria decision making. IEEE Transactions on Systems, Man and Cybernetics, v.18, n.1, p.183-190, 1988.

YAHNER, R. H. Changes in wildlife communities near edges. Conservation Biology, v.2, p.333-339, 1998.

ZAVATINI, J. A.; CANO, H. Variações do ritmo pluvial na bacia do rio Corumbataí - SP.

Boletim de Geografia Teorética, v.23, p.215-240, 1993. 